\title{
ESTUDO MORFOLÓGICO MACRO E MICROSCÓPICO DA GASTRITE CÁUSTICA EM RATOS
}

\author{
MACRO AND MICROSCOPIC MORPHOLOGY OF CAUSTIC GASTRITIS IN RATS
}

\author{
Andy Petroianu, TCBC-MG ${ }^{1}$ \\ Cibele Grossi Rocha ${ }^{2}$ \\ Luiz Ronaldo Alberti ${ }^{3}$ \\ Aline M. Camargos da Costa ${ }^{4}$
}

\begin{abstract}
RESUMO: Objetivos: A ingestão de álcalis provoca graves lesões no tubo digestório alto. A comercialização de substâncias cáusticas em forma líquida facilita o seu uso com intenções suicidas e torna as afecções por elas provocadas relativamente comuns. Nesse sentido, o objetivo do presente trabalho foi avaliar as conseqüências morfológicas da infusão de substância cáustica no estômago murino. Método: Foram estudados 20 ratos Wistar adultos, de ambos os sexos. Após jejum alimentar de 12 horas, instilou-se $1 \mathrm{ml}$ de hidróxido de sódio $(\mathrm{NaOH})$ a $5 \%$ através de cateter orogástrico. Os ratos foram divididos aleatoriamente em quatro grupos $(\mathrm{n}=5)$, de acordo com o tempo de acompanhamento: 24 horas, sete dias, 30 dias e 90 dias, respectivamente. Decorrido o tempo de acompanhamento, os ratos foram mortos e seus estômagos foram avaliados macro e microscopicamente. Resultados: Após 24 horas, os estômagos estavam dilatados e com aderências ao fígado, omentos e pâncreas. Suas mucosa e submucosa apresentavam áreas de necrose de coagulação do corpo e do antro entremeada por intensa infiltração bacteriana. Após sete dias, os estômagos permaneciam dilatados e mantendo o mesmo padrão necrótico anterior, porém sem os focos sépticos. Nos grupos de um e três meses, a cavidade abdominal teve aspecto normal. Os estômagos apresentavam consistência endurecida e com proliferação fibrovascular. Conclusão: Os animais que sobreviveram à necrose e à intensa infiltração bacteriana da primeira semana desenvolveram reparação progressiva de seus estômagos, porém acompanhada de complicações decorrentes da fibrose cicatricial.
\end{abstract}

Descritores: Estômago; Cáusticos-ingestão; Gastrite; Complicações.

\section{INTRODUÇÃO}

A ingestão de substâncias corrosivas é uma ocorrência relativamente comum na prática médica. A maior parte ocorre antes dos cinco anos, por ingestões acidentais. $\mathrm{O}$ outro pico ocorre na faixa dos 20 aos 30 anos, por ingestões intencionais ${ }^{1}$.

$\mathrm{O}$ estudo de doentes que ingerem produtos químicos lesivos ao sistema digestório revelou a multiplicidade de seus aspectos clínicos, anatômicos e terapêuticos. Alguns fatores podem ser determinantes da maior ou menor gravidade das lesões provocadas, como o tipo de substância ingerida, sua quantidade e concentração, a forma de apresentação (sólida, líquida e pastosa), caráter acidental ou intencional da ingestão, estado de repleção ou vacuidade do órgão digestório, além da ocorrência de regurgitação ou vômitos ${ }^{2}$.

É variável a incidência dos casos (acidentais ou não) de ingestão de substâncias agressivas ao tubo digestório, sendo verificada uma redução nas últimas décadas ${ }^{3}$. Existe

1. Professor Titular do Departamento de Cirurgia da Faculdade de Medicina - UFMG, Docente-Livre da Faculdade de Medicina de Ribeirão Preto - USP, Docente-Livre da Escola Paulista de Medicina - UNIFESP, Doutor em Fisiologia e Farmacologia, Pesquisador IA do CNPq

2. Residente de Neurologia da Santa Casa de Belo Horizonte

3. Acadêmico de Medicina da Faculdade de Ciências Médicas de Minas Gerais, Bolsista de Iniciação Científica do CNPq

4. Residente de Oftalmologia da Santa Casa de Belo Horizonte

Recebido em 05/10/2000

Aceito para publicação em 27/06/2001

Trabalho realizado no Departamento de Cirurgia, Faculdade de Medicina, Universidade Federal de Minas Gerais, com apoio do CNPq e FAPEMIG. 
variação também em relação à zona urbana e rural, sendo maior nesta última.

No Brasil o hidróxido de sódio $(\mathrm{NaOH})$, conhecido como soda cáustica, é o agente químico que mais provoca lesões cáusticas. Há também casos de ingestão de ácidos, principalmente o clorídrico, responsáveis por esofagite e gastrite corrosivas ${ }^{2}$. Grande parte dos acidentes é de natureza leve, pois a criança consegue cuspir parte do produto, assim que uma sensação de queimação se produz, poupando o esôfago e o estômago. Entretanto, lesões de lábios, língua, faringe e laringe são inevitáveis. Em alguns casos, sobrevêm lesões mais distais associadas às do sistema respiratório ${ }^{4}$.

As feridas provocadas no esôfago e estômago por ingestão de cáusticos habitualmente são graves e progressivas. Se ocorrer a ingestão de substâncias com alto poder corrosivo, mesmo em quantidade pequena, suas conseqüências serão graves. Pode ocorrer também aspiração do cáustico, com edema e lesões de vias aéreas, provocando desconforto respiratório imediato e elevado risco à vida.

No Brasil, não são observadas normas que limitem a comercialização de produtos cáusticos. Soda cáustica pura e dezenas de outros produtos com ação cáustica são encontrados em prateleiras de supermercados, em recipientes facilmente manipuláveis ${ }^{5}$. Em países onde leis rigorosas determinam a comercialização apenas de produtos com concentrações de cáusticos de até $10 \%$, e em embalagens que dificultam o manuseio por crianças, houve um declínio significativo na incidência de ingestão destes agentes e suas complicações ${ }^{6-8}$. Assim, o ácido clorídrico é relatado com maior freqüência nos EUA, onde a comercialização da soda cáustica é rigidamente controlada, desde o princípio do século ${ }^{2,9}$. Na Finlândia, a soda cáustica também não é livremente disponível e não há acidentes por sua ingestão desde 1969.

Os casos de esofagite química ultimamente descritos, em crianças, têm como agentes os detergentes de lavar pratos e substância alcalina não especificada.

É importante conhecer a evolução anatomopatológica das lesões provocadas por agentes cáusticos porque há nítida correlação entre esse e o quadro clínico do paciente. Compreende-se, assim, que diante de uma evolução clínica favorável, as lesões tendem a ser mais superficiais e limitadas. Quando ocorrem manifestações de dor, agitação ou prostração, febre e toxemia, é muito provável que as lesões sejam profundas ou extensas ${ }^{2}$.

O objetivo do presente trabalho foi avaliar as alterações morfológicas do estômago após a infusão de cáustico em rato em um período de três meses.

\section{MÉTODO}

Foram estudados 20 ratos albinos da raça Wistar, pesando entre 250 e 400 gramas. Todo o experimento foi conduzido de acordo com as normas éticas para experimentação animal, segundo a Declaração de Helsinque. $\mathrm{O}$ trabalho foi aprovado por Comissão de Ética da UFMG.
Após jejum alimentar de 12 horas, os ratos foram submetidos à anestesia inalatória com éter sulfúrico. Em seguida, foi introduzido um cateter orogástrico número 6 , através do qual foi injetado $1 \mathrm{ml}$ de hidróxido de sódio a $5 \%$. Os ratos foram acompanhados após o procedimento até a sua recuperação anestésica, avaliando-se movimentos respiratórios, coloração de mucosas e batimentos cardíacos. Eles foram então divididos aleatoriamente em quatro grupos $(\mathrm{n}=5)$ de acordo com o tempo de acompanhamento:

- Grupo I: animais avaliados 24 horas após injeção da substância cáustica.

- Grupo II: animais avaliados após sete dias.

- Grupo III: animais avaliados após 30 dias.

- Grupo IV: animais avaliados após 90 dias.

Os ratos foram acompanhados diariamente e receberam água e ração para rato à vontade. Decorrido o tempo de acompanhamento, os animais foram mortos com dose inalatória letal de éter sulfúrico.

A cavidade abdominal e seus órgãos foram cuidadosamente estudados através de laparotomia. Em seguida, os estômagos foram retirados com secções no esôfago e duodeno a 2 centímetros do estômago. $\mathrm{O}$ órgão foi completamente aberto pela curvatura maior.

Biópsias do estômago, esôfago e duodeno foram retiradas e fixadas em formol a $10 \%$. Posteriormente, os segmentos retirados foram processados histologicamente e corados com hematoxilina-eosina e tricrômio de Gomori para estudo microscópico.

\section{RESULTADOS}

No Grupo I, após um dia, verificou-se dilatação gástrica acentuada, com aderências a fígado, omentos e pâncreas. $\mathrm{O}$ esôfago estava sem alterações macroscópicas. $\mathrm{O}$ duodeno mostrava-se espessado e com coloração escura. O exame microscópico revelou necrose de coagulação da mucosa e submucosa do corpo e antro gástricos, e do duodeno, entremeada por intensa infiltração bacteriana, com relativa preservação do fundo gástrico. Não foi encontrado sinal de perfuração. As camadas externas de músculo liso não foram atingidas pela necrose química, mas estavam infiltradas por células inflamatórias características de processo agudo, com a presença de polimorfonucleares. Havia numerosos focos necróticos na parede das veias associados a trombos recentes.

No Grupo II, após sete dias, os estômagos estavam dilatados e mantendo o mesmo padrão necrótico verificado após 24 horas, porém sem focos sépticos e com dilatações focais do intestino delgado. Observaram-se aderências do estômago aos órgãos vizinhos. A parte distal do estômago estava retraída e com necrose de liquefação. Apenas o fundo gástrico foi preservado. Áreas de necrose eram entremeadas por tecido de granulação. Observou-se um caso de fístula esofagobrônquica. 
Os animais dos grupos (Grupos III e IV) apresentavam a cavidade abdominal com aspecto próximo à normalidade, mantendo-se íntegros os compartimentos infra e supramesocólicos. Foram encontradas ainda aderências frouxas a órgãos vizinhos. Os estômagos tiveram tamanho e forma normais, porém com consistência endurecida. Sua serosa era brilhante e sem deposição de fibrina. Não houve sinais de perfuração ou necrose (Figura 1). Histologicamente, havia proliferação de tecido fibrovascular denso acompanhado de infiltrado mononuclear e áreas com alterações regenerativas. $\mathrm{O}$ esôfago e o duodeno não tiveram alterações macro e microscópicas evidentes. O fígado era de aspecto normal, sem sinais de congestão. Um rato do Grupo IV mostrou significativa diminuição de peso (de $280 \mathrm{~g}$ para $150 \mathrm{~g}$ ) em 90 dias, sendo que a necropsia mostrou estenose antral. Um rato do Grupo III morreu nas primeiras 72 horas após instilação do álcali. Sua cavidade abdominal mostrava sinais de peritonite, o estômago não havia sido perfurado. Entretanto, a parede gástrica mostrava-se com intensa infiltração bacteriana e vários focos necróticos.

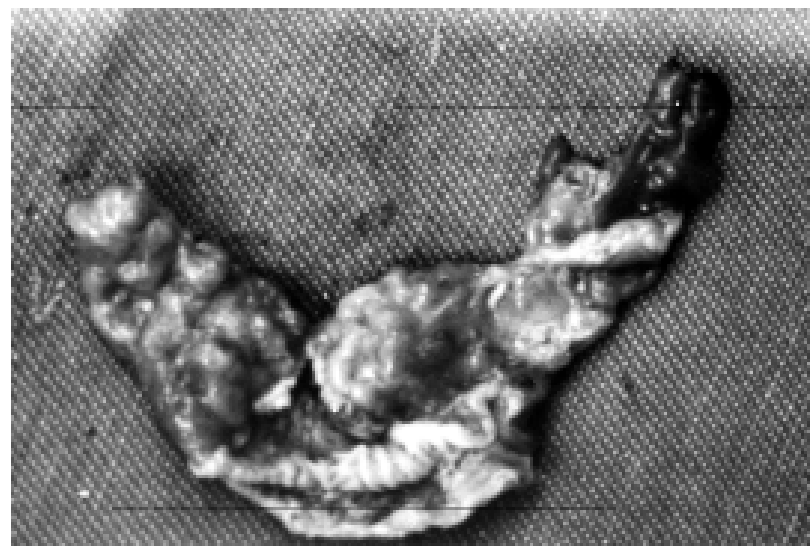

Figura 1 - Estômago aberto no $30^{\circ}$ dia após injeção de hidróxido de sódio. Observar a mucosa retraída e edemaciada.

\section{DISCUSSÃO}

A ingestão de cáusticos acompanha-se de muitas complicações, com conseqüências graves a curto e a longo prazos. As substâncias cáusticas provocam lesões em todos os tecidos orgânicos com que entram em contato. Todavia, superada a fase aguda da agressão, a resposta biológica é diferente para cada tecido. Na pele, as lesões evoluem com escaras e posterior reepitelização. Isso não sucede na mucosa gástrica, em que a epitelização é dificultada pela justaposição das paredes, por ter um lume virtual. Deste modo, no piloro, após a saída das escaras, segue-se proliferação colágena, com conseqüente estenose ${ }^{10}$.
No estômago, os cáusticos percorrem a curvatura menor, à semelhança do bolo alimentar e são detidos no antro pelo espasmo pilórico ${ }^{10,11}$. No antro, as substâncias provocam necrose tecidual que pode comprometer todas as camadas da parede gástrica, até perfurá-la ${ }^{12}$. Na maioria das vezes, todavia, a necrose restringe-se à mucosa e à submucosa, dada a pequena quantidade de cáustico que chega ao órgão. Nenhum dos ratos avaliados teve o estômago perfurado. Entretanto, no projeto-piloto, em que se instilou dose maior de cáustico (30\%), cinco de oito ratos estudados morreram nas primeiras 24 horas e a necropsia mostrou perfuração de víscera.

De acordo com a literatura, nas áreas necrosadas, há destruição glandular e segue-se intensa proliferação colágena na submucosa que se estende à muscular ${ }^{4,13-15}$. $O$ presente trabalho também encontrou esse fato, todavia não foi possível analisar quantitativamente a deposição colágena. A histometria poderia, eventualmente, quantificar de maneira mais adequada os nossos resultados, permitindo assim uma análise estatística. Entretanto, a multiplicidade morfológica não permitiu tal estudo sem a inconveniente interferência de uma avaliação subjetiva.

No antro gástrico, por sua reduzida luz, a retração cicatricial gera estenoses anulares que podem levar à oclusão e à suboclusão ${ }^{16}$. Nesse sentido, um rato do Grupo 4 apresentou diminuição de peso a partir do primeiro mês, sendo que a necropsia revelou estenose importante do antro. Esse fato alerta para a importância de se pesquisar a presença de estenose antropilórica em pacientes com história de ingestão de cáusticos, mesmo que as queixas sejam apenas esofágicas.

Além de perfurações gástricas, podem ser observadas complicações menos freqüentes, como fístulas gastrocólicas, esofagobrônquicas. No Grupo II houve uma fístula esofagobrônquica, atribuível a um possível refluxo do material instilado, acometendo o esôfago. Esse fato reforça a necessidade de se estudar sinais de desconforto respiratório, como estridor e outras alterações respiratórias, já que eles podem associar-se a seqüelas posteriores e a uma elevada mortalidade ${ }^{17}$.

Alguns trabalhos evidenciaram uma incidência próxima de 5\% de neoplasia esofágica entre pacientes com história de acidente cáustico na infância ${ }^{18}$. Sabendo-se que a doença do refluxo pode ser precoce, nesses casos, a lesão cáustica gástrica poderia estar envolvida na patogênese de tal neoplasia.

Concluindo, os achados encontrados no presente trabalho denotam a necessidade de uma avaliação imediata e acurada após a ingestão de substâncias cáusticas. Os animais que sobreviveram à necrose e à intensa infiltração bacteriana da primeira semana evoluíram com reparação progressiva de seus estômagos, porém acompanhada de complicações decorrentes da fibrose cicatricial. 


\begin{abstract}
Background: Alkali ingestion causes severe injuries in the upper gastrointestinal tract. Currently, a large variety of these agents may be found in liquid form, increasing their use in suicide attempts and accidental ingestion. The goal of the present study was to evaluate morphological effects of alkali ingestion in murine stomach. Method: Twenty adult rats, of both sexes were submitted to $\mathrm{NaOH}-5 \%$ gastric infusion through an orogastric catheter. Rats were randomly divided into four groups $(n=5)$, and studied after 24 hours, 7 days, 30 days and 90 days, respectively. The animals were killed and their stomach and abdominal cavity were assessed. Results: After 24 hours, mucosa and submucosa presented coagulation necrosis, with a mild acute transmural inflammation with polymorphonuclear infiltration and numerous necrotic focci. After 7 days, the necrotic aspect was the same, but with no necrosis. In the groups of 30 and 90 days the abdominal cavity recovered its normal aspect. Stomachs showed fibrosis, rigidity and fibrovascular proliferation. Conclusion: The rats that survived to necrosis and bacterial infiltration during the first weeks, developed progressive healing of their stomachs, maintaining the risk of complications due to intense fibrosis.
\end{abstract}

Key Words: Stomachs; Caustic ingestion; Gastritis; Complications.

\section{REFERÊNCIAS}

1. Rothstein FC.Caustic injuries to the esophagus in children. Pediatr Clin North Am 1986; 33: 665-722.

2. Viana AT, Chamlian EG, Barros RB et al. Esofagite e gastrite cáusticas. In: Petroianu A. Urgências Clínicas e Cirúrgicas. $1^{\text {a }}$ Edição. Rio de Janeiro. Guanabara Koogan 2001 (no prelo).

3. Barreto PM. Lesões cáusticas do esôfago. In: Corrêa Neto A. Clínica Cirúrgica. São Paulo. Fundo Editorial Procienx, 1996; 4: 117-36.

4. Viana AT. Estenose antropilórica por cáusticos ou corrosivos. Acta Cir Bras 1988; 3:95-102.

5. Filho ES, Araújo OR. Lesões por ingestão. Wasserman RL, Ginsburg CM. Caustic substance injuries. J Pediatr 1985; 107:169-74.

6. Wasserman RL, Ginsburg CM. Caustic substance injuries. J Pediatr 1985; 107:169-74.

7. Nuutinem M, Uhari M. Consequences of caustic ingestions in children. Acta Pediatr 1994; 83:1200-5.

8. Christesen HBT. Epidemiology and prevention of caustic ingestions in children. Acta Pediatr 1994; 83:212-15.

9. Tucker JA, Turtz MC, Silberman HD et al. Tucker retrograde esophageal dilatation 1924-1974. Ann Otol Rhinol Laryngol 1974; 83: 3-35.

10. Hodgson JH. Corrosive structure of the stomach; case report and review of literature. Br J Surg 1959; 46:358-61.

11. Maggi AL, Meeroff M. Stenosis of the stomach caused by corrosive gastrits. Gastroenterol 1953; 24:573-8.

12. Gagliardi D, Oliveira C, Minas RM. Necrose esofagogastroduodenal por ingestão de soda cáustica. Arq Med Fac Ciências Med Santa Casa SP 1986; 6-92-4.
13. Spitz L, Lakhoo K. Caustic ingestion. Arch Dis Child 1993; 68:157-8.

14. Gago O, Ritter FN, Martel W et al. Aggressive surgical treatment for caustic injury of the esophagus and stomach. Ann Thorac Surg 1972; 3:243-50.

15. Hsu CP, Chen CY, Hsu NY et al. Surgical treatment and its long-term result for caustic-induced prepyloric obstruction. Eur J Sur 1997; 163:275-9.

16. Viana AT. Ostomias na estenose cáustica. Arq Bras Cir Dig 1997; 12:81.

17. Vergauwen P, Moulin D. Caustic burns of the upper digestive and respiratory tracts. Eur J Pediatr 1991; 150:700-3.

18. Rothstein FC. Caustic injuries to the esophagus in children. Pediatr Clin North Am 1986; 33:665-722.

Endereço para correspondência:

Prof. Andy Petroianu

Av. Afonso Pena, no 1626, apto. 1901.

30130-005, Belo Horizonte-MG. 